\title{
PARETO-IMPROVING INDIRECT TAX COORDINATION AND TAX DI-
}

VERSITY

Christos Kotsogiannis $^{a}$ and Miguel-Angel Lopez-Garcia ${ }^{b}$

${ }^{a}$ Tax Administration Research Center (TARC), Department of Economics, University of Exeter Business School, Streatham Court, Rennes Drive, EX4 4PU, England, UK, and CESIfo, Munich, Germany. E-mail: c.kotsogiannis@exeter.ac.uk;

${ }^{b}$ Departamento de Economia Aplicada, Universidad Autonoma de Barcelona, 08193 Bellaterra, Barcelona, Spain. E-mail: miguelangel.lopez@uab.cat 
Abstract: Coordination in tax matters, in the EU and elsewhere, has been largely driven by the movement of taxes towards some common level and, therefore, towards tax uniformity. Making use of a perfectly competitive general equilibrium framework of international trade in which governments provide global public goods, it is shown that, starting from a Nash equilibrium, there exist strict Pareto-improving multilateral tax reforms that are consistent with tax diversity.

Keywords: Indirect tax coordination; tax diversity; reform of commodity taxes; global public goods.

JEL classification: F15; H21; H41; H87.

Funding: This work was supported by the Economic and Social Research Council [ES/S00713X/1, Kotsogiannis] and the Spanish Ministry of Science, Innovation and Universities [RTI2018095799-B-I00, Lopez-Garcia].

Acknowledgements: We thank two anonymous referees for comments and advice and the participants at the International Conference on Public Policy: Practice and Reform, Delphi, Greece, and the 2st Catalan Economic Society Conference, Barcelona, for comments on an earlier draft of this paper. 


\section{Introduction}

A concern in countries designing their commodity tax system is the fear that their tax base will shift elsewhere if commodity taxes are domestically higher than elsewhere. This concern is reflected in tax legislation in the EU, and elsewhere (as in Australia and Canada), of provision for tax coordination and tax harmonization. Whatever their precise form (considered more closely shortly below), it is the existence of such spillovers that create a prima facie case for central coordination of tax matters across countries, since lack of it will result in outcomes that are inefficient from a global perspective. In the EU, for example, Directive 2006/112/EC - a recast of the Sixth value-added-tax (VAT) Directive of 1977-has achieved some degree of tax harmonization with the common bands of VAT, which require a minimum VAT rate of $15 \%$ on all products (apart from exemptions and special authorisations). ${ }^{1}$

Unsurprisingly, the appropriate form of tax harmonization has been the focus of the academic literature, and policy discussions, in the last two decades. ${ }^{2}$ One of the results in this literature is that, in the absence of public revenue effects, a move towards more tax uniformity can generate potential Pareto improvements, in the sense that at least one of the tax-harmonizing countries will strictly gain, and none lose, as a consequence of tax harmonization. ${ }^{3}$ The intuition behind this relies, broadly, on the fact that a tax harmonizing reform, by keeping producer prices fixed, results in an improvement of exchange efficiency by taking into account the demand responses of the tax-harmonizing countries. ${ }^{4}$ Unsurprisingly, the desirability of tax-harmonizing reforms diminishes if one accounts for the allocation of tax revenues in the form of either local or global public goods. In this case additional restrictions are required (either on the effects of the reforms on tax revenues and/or availability of unrequited transfers). There is a simple

\footnotetext{
${ }^{1}$ Excise duties are also subject to minimum rates, based on Articles 191-192 of the Treaty on the Functioning of the European Union. There are, of course, forms of harmonization: one possibility is the harmonization of some policy parameters (rate and base), whereas another one is when countries set tax policy parameters independently, and rely primarily on exchange of information to resolve issues related to the taxation of intra-community trade. The analysis here focuses on the former.

${ }^{2}$ Early contributions are Keen $(1987,1989)$ and Turunen-Red and Woodland (1990). In the EU context, the Single European Act, by requiring unanimity in tax matters, has endowed Member States with a veto power that ensures that only Pareto-improving tax reforms will be adopted (assuming that Member States do not vote strategically).

${ }^{3}$ An actual Pareto improvement - where all participating countries strictly gain in welfare -is more difficult to establish. On this see Keen (1989) for destination-based indirect taxes, and Lopez-Garcia (1996) for origin-based taxes (commodities are taxed by, and revenues accrue to, the country that produces them). The market structure also matters, Keen, Lahiri and Raimondos-Møller (2002).

${ }^{4}$ This conclusion is general enough to encompass the origin-based principle of indirect taxes, with the supply responses being the critical factor and producer prices being kept constant, Lopez-Garcia (1996).
} 
reason for this: tax-harmonization is not capable - by way of design - to deal with 'two margins', one arising from the intensity of preferences for public goods, and one arising from inefficiencies in either consumption or production. ${ }^{5}$

While this perspective is clearly an important one, an understanding of the requirements of a tax-coordinating policy that maintains tax diversity is also valuable. This resonates very strongly with the view that tax diversity allows '... member states maximum flexibility in arranging their tax system without, of course, interfering with the establishment of an internal market,' Cnossen (1990), p.473. ${ }^{6}$ The issue then is not one of harmonizing taxes but '... how much tax diversity ${ }^{7}$ can be permitted without interfering with the establishment of a common market ...', Cnossen (1990), p.473. This is also the perspective taken by the EU, and expressed in the European Commission's tax policy strategy (COM (2001) 260), which emphasizes that there is no need for an across the board harmonization of EU Member States' tax systems: Member States are free to choose the tax systems that they consider most appropriate and according to their preferences. But while it is easy to find statements of the importance of tax diversity for tax design and implementation, the technical literature has neglected the issue.

The aim in this paper is therefore to explore the welfare implications of taxcoordinating reforms that maintain and can even foster tax diversity. It does so by characterizing both potential and actual Pareto-improving multilateral tax reforms within a standard general equilibrium model of competitive trade in many goods in which the policy instruments are destination-based commodity taxes, and tax revenues finance public goods that are global in nature. The paper also elaborates, in passing, on the condition required for a tax reform that approaches optimal taxes to generate a potential Pareto improvement. Interestingly, and against what appears to be a commonly held view, such a tax reform does not always generate Pareto improvements: it does so only if the initial tax structures are close enough to the optimal ones.

The organization of the paper is the following. Section 2 provides the background against which the analysis is developed. Section 3 characterizes the country-specific target-vectors that are at the core of the analysis, presents the reforms and discusses their implications in terms of tax diversity. In the case of a potential Pareto improvement, the target vectors are obtained using the optimal tax formula but evaluated at actual taxes (Proposition 1). When the purpose is to achieve an actual Pareto improvement, the

\footnotetext{
${ }^{5}$ See, for instance, Delipalla (1997), Lockwood (1997), Lahiri and Raimondos-Møller (1998), LopezGarcia (1998), Kotsogiannis and Lopez-Garcia (2007) for the case of local public goods, and Karakosta, Kotsogiannis and Lopez-Garcia (2014) for the case of global public goods and within an imperfectly competitive environment.

${ }^{6}$ See also Scott (1987).

${ }^{7}$ Emphasis added.
} 
country-specific target vectors involve a re-scale of the tax structures prevailing at the initial Nash equilibrium (Proposition 2). Section 4 provides some illustrative examples. Section 5 summarizes the results and provides some further remarks.

\section{The model}

To formalize ideas, use is made of a standard general equilibrium two-country small-openeconomy competitive trade model where governments levy commodity taxes and provide global public goods. The two countries are labeled 'home' and 'foreign', and variables pertaining to the home and foreign country are denoted, respectively, by lower- and upper case letters. In each country there is a private sector which produces $M+1$ tradeable commodities and a public one which produces a non-tradeable public good $g(G)$. This public good is global in the sense that the enjoyment of the good by the home (foreign) country resident does not diminish its availability for the citizen in the foreign (home) country. ${ }^{8}$ Commodity taxation is destination-based in the sense that commodities are taxed by - and revenues accrue to - the country where final consumption takes place. Unrequited transfers between governments are not available.

In the home (foreign) country there is a single representative consumer with preferences described by an expenditure function

$$
e(u, q, g, G) \equiv \min _{x}\left\{q^{\prime} x \mid \hat{u}(x, g, G) \geq u\right\} \quad ; \quad E(U, Q, g, G) \equiv \min _{X}\left\{Q^{\prime} X \mid \hat{U}(X, G, g) \geq U\right\}
$$

where $x(X)$ is the vector of consumption of the $M+1$ private goods, $u(U)$ is the utility of the consumer, and $q(Q)$ is the $M+1$-vector of consumer prices. ${ }^{9}$ The vector of compensated demands in the home (foreign) country is given by $e_{q}\left(E_{Q}\right)$, and $-e_{g}>0\left(-E_{g}>0\right)$ gives the marginal willingness to pay for the public good $g$ by the home (foreign) consumer respectively, or, equivalently, the marginal rate of substitution

\footnotetext{
${ }^{8}$ Sandmo (2006) provides a comprehensive analysis of optimal global public goods provision. Examples of global public goods abound: clean up environmental activities, global security and global protection of communicable diseases, to name a few. Assessing pure global public goods from public accounts is not trivial and requires a detailed knowledge of those goods. Nevertheless, the numbers suggest that they are substantial. In 2014 in the EU-28, for example, these goods accounted for $37.1 \%$ of total expenditure (these items include: general public services (13.9\%), defence (2.8\%), public order and safety $(3.7 \%)$ environmental protection $(1.7 \%)$, health (15\%)-excluding social protection at $40.4 \%$ of total expenditure, source: Eurostat. There are examples of other global public goods which are more local, such as disputes between neighboring countries over river rights, for example. The framework does not distinguish between the two types, pure-global and local-global. Notice that no restriction is made on the precise functional form of the public goods - the framework is flexible enough to accommodate public goods whose impact is given by the sum of the public goods provided in the two countries.
}

${ }^{9}$ All vectors are column vectors, with a prime indicating transposition. A subscript denotes differentiation. 
between $g$ and the numeraire good, denoted by $m r s_{g}\left(M R S_{g}\right)$. Notice that the utility specification, implicit in (1), does not place any restrictions on the relationship between the two public goods, $g$ and $G$.

The private sector is competitive and characterized by a restricted revenue function denoted by $r(p, g)(R(P, G))$ for the home (foreign) country. The vector of supplies in the home (foreign) country is given by $r_{p}\left(R_{p}\right)$, and $r_{g}<0\left(R_{G}<0\right)$ gives the reduction in the home (foreign) country's production of the tradeable goods - and so revenues $r(p, g)(R(p, G))$ - as a consequence of an increase in the production of the global public good. The global public goods $g$ and $G$ are produced with technology that exhibits constant returns to scale, implying that the marginal cost of production (the marginal rate of transformation between the domestically supplied global public good $g(G)$ and the numeraire in the home (foreign) country, denoted by $\operatorname{mrt}_{g}\left(M R T_{g}\right)$ ), is given by $-r_{g}>0\left(-R_{G}>0\right){ }^{10}$

To focus on issues arising from the global nature of the public goods, rather than the well-known tax-setting incentives of countries arising through terms-of-trade, the analysis will pay attention to two small open economies trading at a fixed international commodity producer-price vector, denoted by $p$. This does not mean that there are no externalities linking the two countries thereby rendering tax-coordination an inefficient international policy. Externalities do exist but they come solely through the global nature of the public goods.

Denoting the destination-based commodity tax-vector in the home country by $t$ and in the foreign one by $T$, the consumer price-vector is given by $q=p+t$ for the home country and $Q=p+T$ for the foreign one. The homogeneity properties of the functions in the variables $q, Q$ and $p$, imply that, without loss of generality, we can take the first tradeable commodity, good 0 , to be the numeraire and also to be the untaxed commodity in both countries, so that $p_{0}=q_{0}=Q_{0}=1$.

An equilibrium for this economy is a set of values for the endogenous variables $\{u, U, g, G\}$ that satisfy the budget constraints of the consumers and governments, given the vector of exogenous tax rates $t, T$. The system of equations that characterizes the

\footnotetext{
${ }^{10}$ The restricted revenue function embeds all the usual properties of technology. On this see Abe (1992) who, too, assumes that $-r_{g}$ and $-R_{G}$ are constant.
} 
equilibrium is given by (a $\left(^{\prime}\right)$ denotes transpose $)^{11}$

$$
\begin{aligned}
e(u, q, g, G) & =r(p, g)+t^{\prime} e_{q}(u, q, g, G), \\
E(U, Q, G, g) & =R(p, G)+T^{\prime} E_{Q}(U, Q, G, g), \\
t^{\prime} e_{q}(u, q, g, G) & =-g r_{g}(p, g), \\
T^{\prime} E_{Q}(U, Q, G, g) & =-G R_{G}(p, G) .
\end{aligned}
$$

Equations (2) and (3) give, respectively, the home and foreign country consumer's budget constraint, ${ }^{12}$ whereas the home and foreign government budget constraints are given by, respectively, equations (4) and (5). ${ }^{13}$

The issues addressed will be analyzed, as it is typically the case, by considering perturbations of the system (2)-(5). In doing so, it will be assumed that $e_{q u}=E_{Q U}=0_{M}$, meaning that in each country income effects attach only to the untaxed numeraire commodity, good $0 .{ }^{14}$ To remove a further inessential complication, it will be also assumed that global public good provision does not affect the compensated demands for, and the supplies of, any good other than the numeraire, and so $e_{q k}=E_{Q k}=r_{p k}=R_{p k}=0_{M}$, $k=g, G$. Utility is therefore additive separable in the private (non-numeraire) goods and the global public good and quasilinear in the numeraire good. ${ }^{15}$

The analysis now proceeds by identifying tax reforms ${ }^{16}\{d t, d T\}$ that generate either a potential or an actual Pareto improvement and can foster tax- and public good diversity. To the best of our knowledge there has been no formal analysis of the type of

\footnotetext{
${ }^{11}$ To model public good production the analysis follows Abe (1992). An alternative specification is to assume, following Keen and Wildasin (2004), that the government purchases the numeraire good and (as, it will be clear shortly below, it is assumed here) the public good use of this good does not affect the compensated demands of the non-numeraire goods. Adopting the present specification the analysis focuses both on the spending side and public good production.

${ }^{12}$ Equation (2) simply states that, in equilibrium, the minimum expenditure of the home consumer required to achieve utility $u$ (given by $e(u, q, g, G$ ), and given commodity prices, $q$, and global public goods, $g$ and $G$ ) is equal to the sum of the revenues generated by the production of the tradeable goods, $r(p, g)$, and the revenues generated by taxing own demand, given by $t^{\prime} e_{q}$. A similar interpretation applies to the budget constraint of the foreign consumer in equation (3).

${ }^{13}$ Since prices are taken as parameters by the countries the market clearing conditions which solves for these these prices can be ignored. As such they do not form part of the system in (2)-(5).

${ }^{14}$ This is a common assumption in the analysis of optimal commodity taxes and tax reforms. See, for example, Keen (1989), Lahiri and Raimondos-Møller (1998) and Keen and Wildasin (2004)

${ }^{15}$ Standard properties of the expenditure function $e(\cdot)$ (and $\left.E(\cdot)\right)$ imply that the $(M+1) \times(M+1)$ matrix of substitution effects (including the untaxed numeraire good) is negative semi-definite. It will further be assumed that there is enough substitutability between the numeraire good and all other goods so that the $M \times M$ matrices $e_{q q}$ and $E_{Q Q}$ are negative definite. See Woodland (1982) and Dixit and Norman (1980).

${ }^{16}$ These reforms are to be understood throughout as 'local' (piecemeal) reforms.
} 
reforms considered here.

\section{Pareto-improving reforms}

Key to the analysis is in recognising that there exist country-specific tax-vector targets $\psi(t, T)$ and $\Psi(T, t)$ - for the home and foreign country, respectively-obtained using the functional forms of the optimal tax structures but evaluated at any arbitrary initial value of the tax structures, $t$ and $T$, and defined as ${ }^{17}$

$$
\psi^{\prime}(t, T) \equiv-(1-\lambda) e_{q}^{\prime}\left[e_{q q}\right]^{-1} \quad ; \quad \Psi^{\prime}(T, t) \equiv-(1-\Lambda) E_{Q}^{\prime}\left[E_{Q Q}\right]^{-1}
$$

where (following the properties of $e(\cdot)$ and $r(\cdot)$ )

$$
\lambda \equiv \frac{r_{g}}{e_{g}+E_{g}}>0 \quad ; \quad \Lambda \equiv \frac{R_{G}}{E_{G}+e_{G}}>0
$$

are the reciprocal of the 'social' (that is, worldwide) marginal cost of public funds associated with the global public goods provided in each country. ${ }^{18}$ The optimal tax structures (details of this are relegated to Appendix A) follow from perturbing the system of equations (2) to (5), after noting that the change in global welfare, $d W$ is given by $e_{u} d u+E_{U} d U$ (where $e_{u}$ and $E_{U}$ are the inverses of the marginal utilities of income ${ }^{19}$ in each country). In doing so one arrives at

$$
d W=C d t+D d T
$$

where $C$ and $D$ are $1 \times M$ vectors. Optimal ('Ramsey') tax rates, $t^{*}$ and $T^{*}$, are given by setting $\partial W / \partial t=C=0_{M}$ and $\partial W / \partial T=D=0_{M}$ and solving these equations simultaneously to give $t^{* \prime}=\psi^{\prime}\left(t^{*}, T^{*}\right)$ and $T^{* \prime}=\Psi^{\prime}\left(T^{*}, t^{*}\right)$. It is now apparent that (6) and (7) above are nothing else but the result of evaluating the functional forms of the optimal tax rates at the arbitrary tax structures associated using the vectors $t$ and $T$.

\footnotetext{
${ }^{17}$ This parallels Neary (1993) but the discussion there is within a framework where public goods are assumed away and tax revenues are returned to consumers in a lump-sum fashion.

${ }^{18}$ On the concept and applications of the marginal cost of public funds see Dahlby (2008).

${ }^{19}$ Which 'convert' welfare changes from utils in each country to units of the numeraire good. The analysis extends to a more general welfare function, at the cost of some additional expositional burden. Consider for example a welfare function of the form $W=W(m, M)$ where $m, M$ is income in the 'home' and 'foreign' country, respectively, and $W_{m}, W_{M}$ are the social marginal utilities of income. Following the properties of the expenditure function the change in welfare can be written as $d W=$ $W_{m} e_{u} d u+W_{M} E_{U} d U$. What this implies is that this the marginal willingness for the public good, $-e_{g}$ $\left(-E_{g}\right)$ is now 'weighted' by $W_{m}\left(W_{M}\right)$. This 'rescaling' will not change qualitatively the results and therefore it is not pursued here.
} 
Equipped with (6) and (7) it is shown in Appendix A that

$$
d W=\frac{1}{\lambda}(t-\psi(t, T))^{\prime} e_{q q} d t+\frac{1}{\Lambda}(T-\Psi(T, t))^{\prime} E_{Q Q} d T
$$

Close inspection of (9) reveals that what matters for global welfare, and for given targets in (6), are:

- The reciprocal of the social marginal cost of public funds, $1 / \lambda=\left(e_{g}+E_{g}\right) / r_{g}$ for the home country, and $1 / \Lambda=\left(E_{G}+e_{G}\right) / R_{G}$ for the foreign one, that is, the ratios between worldwide marginal valuations and marginal costs of the global public goods in both countries;

- The two countries' compensated demand responses, $e_{q q}$ and $E_{Q Q}$;

- The deviation of the home (foreign) country's actual tax vector, $t$ (and $T$ ), from the country-specific tax-vector target $\psi(t, T)(\Psi(T, t))$.

Now consider a tax reform that implies a non-uniform proportional movement of (at least) one tax-vector towards the country-specific tax-vector targets given by (6), that is,

$$
\left[\begin{array}{c}
d t \\
d T
\end{array}\right]=\left[\begin{array}{c}
\gamma(\psi(t, T)-t) \\
\Gamma(\Psi(T, t)-T)
\end{array}\right]
$$

where $\gamma, \Gamma \geq 0$ give the speed of movement (with the equality sign allowing for the possibility that one of the two countries keeps its tax structure unchanged to its initial value). Clearly, this reform is not only a coordinating one but it is also consistent with tax diversity: For the target-tax structures $\psi(t, T)$ and $\Psi(T, t)$ depend on the marginal valuations of the public goods in both countries, and any movement in a given country's tax structure towards its target accounts not only for this country's preferences but also for the others'.

Substituting (10) into (9), the effect on global welfare of this reform is given by

$$
d W=\theta(t-\psi(t, T))^{\prime} e_{q q}(t-\psi(t, T))+\Theta(T-\Psi(T, t))^{\prime} E_{Q Q}(T-\Psi(T, t))>0,
$$

where

$$
\theta \equiv-\frac{\gamma}{\lambda}<0 \quad ; \quad \Theta \equiv-\frac{\Gamma}{\Lambda}<0
$$

and the inequality sign in (11) follows from the fact that $e_{q q}$ and $E_{Q Q}$ are negative definite.

A sharp result then emerges quite quickly. ${ }^{20}$

\footnotetext{
${ }^{20}$ It is worth noting that the literature has focused on reforms that approach optimal (Ramsey) taxes.
} 
Proposition 1 Starting from any arbitrary tax-distorting equilibrium with $t \neq T$, tax coordination in the sense of (10), and thus a non-uniform reduction in at least one country of the gap between the actual tax-vectors $t(T)$ and the country-specific targets $\psi(t, T)(\Psi(T, t))$, generates a potential Pareto improvement.

This reform preserves tax and global public goods diversity that reflects the countries' preferences for the global public goods, as reflected in the tax structures taken as a starting point. It is also one that does not require the availability of unrequited transfers across governments. But its generality does not lend itself to policy prescriptions. To facilitate this, the analysis now proceeds by characterizing the initial tax structures. A typical, and quite appealing, equilibrium to consider is that of non-cooperative behaviour. ${ }^{21}$ This, as it will be shown shortly below, is an initial situation in which the tax reforms not only deliver potential but also actual Pareto improvements.

Denoting the non-cooperative equilibrium by $N$, home and foreign country taxvectors $^{22}$ are given by, respectively,

$$
t^{N^{\prime}}=-\left(1-\pi^{N}\right) e_{q}^{N \prime}\left[e_{q q}^{N}\right]^{-1} ; T^{N \prime}=-\left(1-\Pi^{N}\right) E_{Q}^{N \prime}\left[E_{Q Q}^{N}\right]^{-1},
$$

where

$$
\pi^{N} \equiv \frac{r_{g}^{N}}{e_{g}^{N}} \in(0,1) \quad ; \quad \Pi^{N} \equiv \frac{R_{G}^{N}}{E_{G}^{N}} \in(0,1) .
$$

Notice that $\pi^{N}\left(\Pi^{N}\right)$ is the reciprocal of the 'private' (that is, in each country) marginal cost of public funds: The marginal loss that, in the perception of the policymaker in the home (foreign) country, the consumer suffers from the tax increase to finance an additional unit of $g(G)$. As shown in Appendix C, $m r s_{g}^{N}>m r t_{g}^{N}$ (with a similar expression for the foreign country) and therefore the non-cooperative equilibrium is inefficient and global public goods are underprovided relative to the Samuelson first-best rule (under the conditions that there are no income effects on the non-numeraire goods and demand and supply of taxed goods are independent of global public good provision). That there is then a case for tax coordination is not surprising. What is, arguably, surprising, as we will immediately see, is that such coordination can also foster tax diversity.

Starting from a non-cooperative equilibrium, the welfare implications of a change

This reform, however, in order to entail a potential Pareto improvement, requires that (and this a much neglected aspect in the literature) the initial tax-distorting equilibrium has to be close enough to the optimum. Appendix B clarifies this point.

${ }^{21}$ At such a Nash equilibrium, each country's tax structure maximizes its own welfare taking the other country's tax structure as given.

${ }^{22}$ The details of this are relegated to Appendix C. 
in the tax vectors in the two countries are given by

$$
e_{u} d u=\frac{e_{G}^{N}}{R_{G}^{N}}\left(E_{Q}^{N \prime}+T^{N \prime} E_{Q Q}^{N}\right) d T \quad ; \quad E_{U} d U=\frac{E_{g}^{N}}{r_{g}^{N}}\left(e_{q}^{N \prime}+t^{N \prime} e_{q q}^{N}\right) d t
$$

To focus on this equilibrium requires the re-scaling of the weights in (6) and its evaluation at the Nash-equilibrium tax structures. Define now the country-specific targets as the result of multiplying the target tax vectors $\psi\left(t^{N}, T^{N}\right)$ and $\Psi\left(T^{N}, t^{N}\right)$ by an expression that depends on the respective social marginal cost of public funds, $1 /\left(1-\lambda^{N}\right)$ and $1 /\left(1-\Lambda^{N}\right)$ in $(7)$. This gives rise to

$$
\omega^{\prime}\left(t^{N}, T^{N}\right)=\frac{1}{1-\lambda^{N}} \psi^{\prime}\left(t^{N}, T^{N}\right) \quad ; \quad \Omega^{\prime}\left(T^{N}, t^{N}\right)=\frac{1}{1-\Lambda^{N}} \Psi^{\prime}\left(T^{N}, t^{N}\right) .
$$

What this transformation of the tax targets in (6) achieves is to account for the divergence between the worldwide marginal valuations and marginal cost in the provision of global public goods (at the non-cooperative equilibrium) which is at the heart of the coordinating reforms. Evaluating (7) at the non-cooperative equilibrium, (16) can be written as

$$
\omega^{\prime}\left(t^{N}, T^{N}\right)=-e_{q}^{N \prime}\left[e_{q q}^{N}\right]^{-1} \quad ; \quad \Omega^{\prime}\left(T^{N}, t^{N}\right)=-E_{Q}^{N \prime}\left[E_{Q Q}^{N}\right]^{-1}
$$

Denoting $\omega^{N}=\omega\left(t^{N}, T^{N}\right)$ and $\Omega^{N}=\Omega\left(T^{N}, t^{N}\right)$, inspection of the vectors $\omega^{N}$ and $\Omega^{N}$ reveals that they are nothing else but a re-scale of $t^{N}$ and $T^{N}$. Indeed, using (13) and (17) one notes that

$$
\omega^{N}=\frac{1}{\left(1-\pi^{N}\right)} t^{N}>t^{N} \quad ; \quad \Omega^{N}=\frac{1}{\left(1-\Pi^{N}\right)} T^{N}>T^{N}
$$

In words, $\omega^{N}$ and $\Omega^{N}$ stretch $t^{N}$ and $T^{N}$ out by the factors $1 /\left(1-\pi^{N}\right)>1$ and $1 /(1-$ $\left.\Pi^{N}\right)>1$ respectively, which is tantamount to saying that the former are radial expansions of the latter.

Consider now a non-uniform proportional movement of one or both countries' noncooperative tax structures towards the country-specific target vectors $\left(\omega^{N}, \Omega^{N}\right)$ in $(17)$, that is

$$
\left[\begin{array}{l}
d t^{N} \\
d T^{N}
\end{array}\right]=\left[\begin{array}{c}
\eta\left(\omega\left(t^{N}, T^{N}\right)-t^{N}\right) \\
H\left(\Omega\left(T^{N}, t^{N}\right)-T^{N}\right)
\end{array}\right]
$$

where $\eta, H \geq 0$ (where, again, the possibility of $\eta$ or $H$ being zero allows for the case where one of the two countries keeps its tax structure unchanged). Notice that $d t^{N}=\left(\eta \pi^{N} /\left(1-\pi^{N}\right)\right) t^{N} \geq 0_{M}$ and $d T^{N}=\left(H \Pi^{N} /\left(1-\Pi^{N}\right)\right) T^{N} \geq 0_{M}$, so that, as a consequence of the multilateral tax reform in (19), at least one of the countries will 
increase its tax rates over and above the initial Nash equilibrium ones.

Using (16), the welfare effects in (15) can be written as

$$
e_{u} d u=\frac{e_{G}^{N}}{R_{G}^{N}}\left[T^{N}-\Omega\left(T^{N}, t^{N}\right)\right]^{\prime} E_{Q Q} d T \quad ; \quad E_{U} d U=\frac{E_{g}^{N}}{r_{g}^{N}}\left[t^{N}-\omega\left(t^{N}, T^{N}\right)\right]^{\prime} e_{q q} d t
$$

Making now use of (19), the utility implications for the home country are then

$$
e_{u} d u=-H \frac{e_{G}^{N}}{R_{G}^{N}}\left(T^{N}-\Omega^{N}\right)^{\prime} E_{Q Q}\left(T^{N}-\Omega^{N}\right)>0
$$

where the inequality follows from the fact that $e_{G}, R_{G}<0$ and $E_{Q Q}$ is a negative definite matrix. A similar expression applies to the foreign country. We thus arrive at:

Proposition 2 Taking as a starting point the non-cooperative Nash equilibrium taxes $t^{N}$ and $T^{N}$ characterised in (13), a multilateral tax-coordinating reform in the sense of (19), and so a radial expansion of each country's tax rates, generates an actual Pareto improvement.

Here $^{23}$ then is a case in which tax coordination that takes the simple form of a nonuniform movement of actual taxes towards an appropriately designed country-specific target vector - and in the absence of terms-of-trade-effects (and unrequited transfers being unavailable) - is conducive to an actual Pareto improvement. Proposition 2 then implies that, conceptually at least, it is possible to achieve welfare gains, both from a global and domestic perspective, that are consistent with, and are the result of, tax diversity. An example will clarify this. ${ }^{24}$

\footnotetext{
${ }^{23}$ The non-cooperative tax-setting implied by the presence of public goods externalities results in outcomes that are inefficient relative to the range of instruments available. The implication is that cooperation, in the form of a multilateral tax reform, is to the advantage of both countries.

${ }^{24}$ It is worth also noticing that the framework is general enough to consider also local public goods, in the sense that the home (foreign) country consumer derives utility only from the provision of the public good $g(G)$. What this implies in modelling terms is that $e_{G}=E_{g}=0$ in (2)-(5). This is the framework used by Lahiri and Raimondos-Møller (1998) to discuss the welfare effects of indirect tax harmonization in the particular case where the commodity tax rates (for the non-numeraire goods) are uniform. With no externalities through public goods present, (6) reduce to $\psi^{\prime}(t, 0) \equiv-(1-\lambda) e_{q}^{\prime}\left[e_{q q}\right]^{-1}, \Psi^{\prime}(T, 0) \equiv$ $-(1-\Lambda) E_{Q}^{\prime}\left[E_{Q Q}\right]^{-1}$, where (following the properties of $e(\cdot)$ and $r(\cdot)$ ), the social and private marginal cost of public funds are the same: $\lambda \equiv r_{g} / e_{g}>0, \Lambda \equiv R_{G} / E_{G}>0$. As a consequence, the essence of Proposition 1 remains unchanged (so does, interestingly, the point made in footnote 20). Thus, the multilateral tax-coordinating reform (10) - that a non-uniform reduction by a least one country of the gap between $t(T)$ and $\psi(t, 0)(\Psi(T, 0))$ - entails a potential Pareto improvement. But there is no counterpart to Proposition 2 since under this case the optimal Ramsey commodity taxes in (A.4) will coincide with the non-cooperative ones.
} 


\section{Examples}

To shed light on the results above, consider the case in which $(i)$ the compensated demands for the tradeable commodities in both countries are independent, so $e_{q q}$ and $E_{Q Q}$ are diagonal matrices (in the sense that $e_{i j}=E_{i j}=0$ when $i \neq j$ ), and exhibit constant elasticities (and so $q_{i} e_{i i} / e_{i}=\bar{\epsilon}_{i i}$ and $Q_{i} E_{i i} / E_{i}=\bar{E}_{i i}$ ); and $(i i)$ the marginal valuations for the public goods in both countries are constant (and denoted by $\bar{e}_{g}, \bar{e}_{G}$, $\left.\bar{E}_{g}, \bar{E}_{G}\right)$, and thus so are $\bar{\pi}, \bar{\Pi}, \bar{\lambda}$ and $\bar{\Lambda} .{ }^{25}$ In this case it is straightforward to see, making use of (13) and (17), that

$$
\begin{gathered}
\frac{t_{i}^{N}}{q_{i}^{N}}=\frac{t_{i}^{N}}{p_{i}+t_{i}^{N}}=-\frac{\left(\bar{e}_{g}-\bar{r}_{g}\right)}{\bar{e}_{g}} \frac{1}{\bar{\epsilon}_{i i}}=-\frac{(1-\bar{\pi})}{\bar{\epsilon}_{i i}} . \\
\frac{\omega_{i}^{N}}{q_{i}^{N}}=\frac{\omega_{i}^{N}}{p_{i}+t_{i}^{N}}=-\frac{1}{\bar{\epsilon}_{i i}}
\end{gathered}
$$

Since $\bar{\pi} \in(0,1)$ it readily follows that $t_{i}^{N}<\omega_{i}^{N}$ (and, following a similar argument, for the foreign country it is the case that $T_{i}^{N}<\Omega_{i}^{N}$ ) implying that the country-specific taxes $\left(\omega^{N}, \Omega^{N}\right)$ are greater than Nash taxes. Estimates for the marginal private (that is, in each country) cost of public funds vary. As a first example, assume, to choose two frequently used estimates, that the home and the foreign country's private marginal cost of public funds are given by, respectively, 1.2 and 2. This then implies (all numbers have been rounded to two decimal points) $\bar{\pi}=0.83$ and $\bar{\Pi}=0.5$. Assume now elasticities in the range of (assuming, for simplicity, that $p_{1}=p_{2}=1$ ) of $\bar{\epsilon}_{11}=\bar{\epsilon}_{22}=-2, \bar{E}_{11}=-1.5$, $\bar{E}_{22}=-1.8$. These ${ }^{26}$ imply $\left(t_{1}^{N}, t_{2}^{N}\right)=(0.09,0.09),\left(T_{1}^{N}, T_{2}^{N}\right)=(0.5,0.38),\left(\omega_{1}^{N}, \omega_{2}^{N}\right)=$ $(0.54,0.54)$ and $\left(\Omega_{1}^{N}, \Omega_{2}^{N}\right)=(1,0.76)$. This example, therefore, illustrates that $\omega_{i}^{N}>t_{i}^{N}$ and $\Omega_{i}^{N}>T_{i}^{N}$, so that the target vectors $\omega^{N}$ and $\Omega^{N}$, following from (19), dictate (assuming $\eta, H=1$ ), tax changes

$$
\left(d t_{1}^{N}, d t_{2}^{N}\right)=(0.45,0.45)>(0,0) \quad ; \quad\left(d T_{1}^{N}, d T_{2}^{N}\right)=(0.5,0.38)>(0,0) .
$$

As stated above, $\left(\omega^{N}, \Omega^{N}\right)$ are radial expansions of $\left(t^{N}, T^{N}\right)$. Therefore, both $t^{N}$ and $\omega^{N}$ on the one hand, and $T^{N}$ and $\Omega^{N}$ on the other, will each be located along the same ray through the origin, so that the direction of the implied tax vectors starting from the Nash

\footnotetext{
${ }^{25} \mathrm{~A}$ utility function that satisfies these assumptions is a quasilinear one (in the numeraire) of separable form - in both private and public goods - that exhibits constant elasticity in the non-numeraire goods and a constant marginal utility for the public goods (for the home country) that is, $u=x_{0}+\sum_{i=1}^{M} a_{i} x_{i}^{b_{i}}+$ $c g+d G$, where $x_{0}, x_{i}$ denote the consumption of the $M+1$ commodities, $a_{i}, c, d>0$ and $0<b_{i}<1$.

${ }^{26}$ The following numbers follow from (22) and (23) computing $t_{i}^{N}=-(1-\bar{\pi}) /\left(\bar{\epsilon}_{i i}+1-\bar{\pi}\right)$ and $\omega_{i}^{N}=-1 /\left(\bar{\epsilon}_{i i}+1-\bar{\pi}\right)$ for the home country and their counterparts for the foreign one.
} 
taxes can be represented in Figure 1. It is clear from mere inspection that the reform approaching $\left(\omega^{N}, \Omega^{N}\right)$ translates into the home (foreign) country's tax structure moving to a point inside (outside) the harmonizing box defined by the coordinates $t^{N} a T^{N} b$. In this case the coordinating reform (19), which by Proposition 2 leads to an actual Pareto improvement, is neither harmonizing nor diversity-enhancing.

\section{Insert Figure 1}

As a second example, suppose now that the private marginal cost of public funds are given by 2 (in home) and 1.66 (in foreign), so that $\bar{\pi}=0.5$ and $\bar{\Pi}=0.6$, and that the elasticities are $\bar{\epsilon}_{11}=-2.5, \bar{\epsilon}_{22}=-1.5, \bar{E}_{11}=-1.73, \bar{E}_{22}=-1.4$, giving rise to $\left(t_{1}^{N}, t_{2}^{N}\right)=$ $(0.25,0.5),\left(T_{1}^{N}, T_{2}^{N}\right)=(0.3,0.4),\left(\omega_{1}^{N}, \omega_{2}^{N}\right)=(0.5,1)$ and $\left(\Omega_{1}^{N}, \Omega_{2}^{N}\right)=(0.75,1)$. The tax changes (assuming again $\eta, H=1$ ) in this case turn out to be

$$
\left(d t_{1}^{N}, d t_{2}^{N}\right)=(0.25,0.5)>(0,0) \quad ; \quad\left(d T_{1}^{N}, d T_{2}^{N}\right)=(0.45,0.6)>(0,0) .
$$

The vectors $\left(\omega^{N}, \Omega^{N}\right)$ and the directions of the reform are represented in Figure 2, starting from the Nash equilibrium tax structures $t^{N}$ and $T^{N}$. In this case, the reform approaching $\left(\omega^{N}, \Omega^{N}\right)$ translates into both countries' tax structures moving to a point outside the harmonizing box $t^{N} c T^{N} d$. Clearly, the situation depicted in Figure 2 shows that a tax-coordinating reform that, by virtue of Proposition 2, implies an actual Pareto improvement, can be fully consistent with a pure notion of tax diversity.

\section{Insert Figure 2}

The two cases depicted in Figures 1 and 2 also allow to illustrate the reform consisting in both countries approaching the tax vectors $\psi(t, T)$ and $\Psi(T, t)$ in $(6)$. Proposition 1 , which is valid for any arbitrary initial position, will in particular hold when the starting point is the non-cooperative equilibrium. Under the conditions of the examples we have

$$
\frac{\psi_{i}}{q_{i}}=\frac{\psi_{i}}{p_{i}+\psi_{i}}=-\frac{\left(\bar{e}_{g}+\bar{E}_{g}-\bar{r}_{g}\right)}{\bar{e}_{g}+\bar{E}_{g}} \frac{1}{\bar{\epsilon}_{i i}}=-\frac{(1-\bar{\lambda})}{\bar{\epsilon}_{i i}},
$$

where $\bar{\lambda}$ is the 'social' (worldwide) marginal cost of public funds associated with the global public good provision in the home country. A bit of algebra shows that $\bar{\lambda}<\bar{\pi}<1$, and as a consequence, $t_{i}^{N}<\psi_{i}$ (and $T_{i}^{N}<\Psi_{i}$ for the foreign country). In terms of the first example we can take $\bar{\lambda}=0.7$ and $\bar{\Lambda}=0.4$ to find $^{27}\left(\psi_{1}, \psi_{2}\right)=(0.17,0.17)$ and

\footnotetext{
${ }^{27}$ The following numbers follow from $(26)$ computing $\psi_{i}=-(1-\bar{\lambda}) /\left(\bar{\epsilon}_{i i}+1-\bar{\lambda}\right)$ for the home country and a similar expression for the foreign one. Notice that assumption (ii) implies that $\bar{\lambda}$ is a constant, and assumption $(i)$ implies that tax rates $\psi_{i}$ are unique.
} 
$\left(\Psi_{1}, \Psi_{2}\right)=(0.66,0.49)$. The implied changes in the tax rates (assuming $\left.\gamma=\Gamma=1\right)$ are

$$
\left(d t_{1}^{N}, d t_{2}^{N}\right)=(0.08,0.08)>(0,0) \quad ; \quad\left(d T_{1}^{N}, d T_{2}^{N}\right)=(0.16,0.11)>(0,0)
$$

In terms of Figure 1, and starting from the Nash equilibrium tax structures $t^{N}$ and $T^{N}$, the reform approaching $(\psi, \Psi)$ translates into the home (foreign) country's tax structure moving to a point inside (outside) the harmonizing box defined by the coordinates $t^{N} a T^{N} b$. As in the case where countries were approaching $\left(\omega^{N}, \Omega^{N}\right)$, the coordinating reform (10), which by Proposition 1 leads to potential Pareto improvement, cannot be characterized either as harmonizing or as diversity-enhancing. ${ }^{28}$

Turning now to the second example, we can take $\bar{\lambda}=0.4$ and $\bar{\Lambda}=0.55$ to find $\left(\psi_{1}, \psi_{2}\right)=(0.31,0.66)$ and $\left(\Psi_{1}, \Psi_{2}\right)=(0.35,0.47)$, which give rise (assuming again $\gamma=$ $\Gamma=1)$ to

$$
\left(d t_{1}^{N}, d t_{2}^{N}\right)=(0.06,0.16)>(0,0) \quad ; \quad\left(d T_{1}^{N}, d T_{2}^{N}\right)=(0.05,0.07)>(0,0) .
$$

As shown in Figure 2, the reform that starts from $\left(t^{N}, T^{N}\right)$ and approaches $(\psi, \Psi)$ leads to both countries' tax structures lying outside the harmonizing box $t^{N} c T^{N} d$. Clearly, this reform is fully consistent with tax diversity and will entail a potential Paretoimprovement.

\section{Conclusion and further remarks}

This paper has argued that simple destination-based tax-coordinating reforms that maintain and even reinforce tax diversity can generate welfare gains. It has also been shown that a non-uniform movement of the tax structure of at least one country towards a country-specific target, where the target results from computing the functional forms of the optimal tax formulas using actual instead of optimal taxes, is potentially Paretoimproving (Proposition 1). When the initial position of the tax structures is the Nash equilibrium, tax-coordinating reforms that are fully consistent with tax diversity can be designed to lead to actual Pareto improvements. These reforms are qualitatively identical to the ones leading to potential welfare gains, the only difference being that the country-specific vectors towards which taxes converge are re-scaled to give rise to radial expansions of Nash taxes (Proposition 2).

It has been noted in passing that (and against a commonly held view) a multilateral reform by which countries approach their optimal (Ramsey) taxes need not be

\footnotetext{
${ }^{28}$ Since $t_{2}^{N} / t_{1}^{N}=\left(\bar{\epsilon}_{11}-\bar{\pi}\right) /\left(\bar{\epsilon}_{22}-\bar{\pi}\right)=\omega_{2}^{N} / \omega_{1}^{N}$ and $\psi_{2} / \psi_{1}=\left(\bar{\epsilon}_{11}-\bar{\lambda}\right) /\left(\bar{\epsilon}_{22}-\bar{\lambda}\right)$, it can easily be shown that the relative position of these rays through the origin will depend on the values of the elasticities $\bar{\epsilon}_{11}$ and $\bar{\epsilon}_{22}$. Figures 1 and 2 show a variety of possibilities.
} 
desirable from a global welfare perspective: it can only be this if the initial tax structures are close enough to the optimal ones. The ('local') reforms characterised in the paper point towards welfare improvements even when the global optimum implies full tax coordination. Consider, for example, the extreme case, where the two countries have identical fundamentals (endowments and preferences) but for some reason different initial tax structures. In this case, moving the tax structures further apart (in a piecemeal fashion) could be conducive to welfare gains. ${ }^{29}$

The analysis here is of course limited in several respects. The market structure has been perfectly competitive and other instruments have been assumed away (for example, trade taxes). ${ }^{30}$ What the analysis here does establish, however, is that although tax coordination in policy discussions has been largely driven by the movement of taxes towards some common level, and therefore towards tax uniformity, there is a strong conceptual case for coordinated tax diversity. There remains much scope for the analysis of tax coordination and tax diversity in richer analytical models. We hope to have shown that the task is worthwhile and that the conclusions can be instructive.

\footnotetext{
${ }^{29}$ We thank an anonymous referee for suggesting this interpretation, whose intuition is as follows. With countries having the same preferences, technologies and endowments, optimal taxes will be identical, $t_{i}^{*}=T_{i}^{*}$ ), as will be those at the Nash equilibrium, $t_{i}^{N}=T_{i}^{N}$. As a consequence, Proposition 2 would not be applicable, and the starting point for the reform must be from initial tax rates $t_{i} \neq T_{i}$. For the sake of simplicity, consider now the situation discussed in the examples of Section 4 . From footnote 26 it follows that $\psi_{i}=\Psi_{i}$, so that (10) implies that both countries are approaching the same target vector. It is then straightforward to show that, from Proposition 1, (10) is potentially Pareto improving but it can be also harmonizing, diversity-enhancing, or neither of the two.

${ }^{30}$ As has the role of the number of countries coordinating in taxes. Elements of this appear in Redoano (2014) who explores the impact of EU membership on tax competition among European countries.
} 


\section{Appendix A: Derivation of (6) and (9)}

This Appendix proceeds by deriving the efficient (the so-called Ramsey) levels of the tax structures, the functional forms of which the country-specific tax-vector targets $\psi(\cdot)$ and $\Psi(\cdot)$ discussed in the main text are based on.

Perturbation of equations (2) and (3), and making use of the fact that $d p=0_{M}$, shows that change in welfare, for each country, depends on change in taxes and the variation in the amounts of the two global public goods. In obvious notation we have that

$$
e_{u} d u=j d t+k d g+n d G \quad ; \quad E_{U} d U=J d T+K d G+N d g,
$$

where $j$ and $J$ are $M \times 1$-vectors and $k, n, N, K$ are scalars. Equations (4) and (5) relate changes in the provision of public goods and the tax reforms in each country as follows

$$
d g=s d t \quad ; \quad d G=S d T
$$

where $s$ and $S$ are scalars. Substituting (A.1) into (A.2) gives

$$
e_{u} d u=\left[\frac{e_{g}-r_{g}}{r_{g}}\left(e_{q}^{\prime}+t^{\prime} e_{q q}\right)+t^{\prime} e_{q q}\right] d t+\frac{e_{G}}{R_{G}}\left(E_{Q}^{\prime}+T^{\prime} E_{Q Q}\right) d T,
$$

and a similar expression for $E_{U} d U$. In words, the welfare in a given country - as a consequence of an arbitrary reform $\{d t, d T\}$-will be affected through two channels. The first one, given by the terms in the square brackets, reflects the welfare impact of a change in its own tax rate, capturing the utility variations associated with, on the one hand, the induced change in its private consumption and, on the other, both the cost and the benefit of its public good provision. The second effect - given by second the term - relates to the welfare implications arising from changes in the other country's global public good provision implied by its own tax change.

Adding (A.3) and its counterpart for the foreign country, the change in global welfare gives (8). Setting $\partial W / \partial t=0_{M}$ and $\partial W / \partial T=0_{M}$ and solving simultaneously, gives the Ramsey taxes

$$
t^{* \prime}=-\left(1-\lambda^{*}\right) e_{q}^{* \prime}\left[e_{q q}^{*}\right]^{-1} \quad ; \quad T^{* \prime}=-\left(1-\Lambda^{*}\right) E_{Q}^{* \prime}\left[E_{Q Q}^{*}\right]^{-1}
$$

where

$$
\lambda^{*} \equiv \frac{r_{g}^{*}}{e_{g}^{*}+E_{g}^{*}} \quad ; \quad \Lambda^{*} \equiv \frac{R_{G}^{*}}{E_{G}^{*}+e_{G}^{*}},
$$

and all the relevant variables have been evaluated at the global optimum, denoted by an $(*) . \lambda^{*}\left(\Lambda^{*}\right)$ is the reciprocal of the social (that is, worldwide) marginal cost of public funds associated with providing global public goods in each country with optimal taxes. ${ }^{31}$

Notice that at the level of Ramsey taxes, global public goods are underprovided relative to the Samuelson first-best rule. To see this, post-multiply the expression in

\footnotetext{
${ }^{31}$ Notice that $\lambda^{*}$ and $\Lambda^{*}$ may be different. This is the consequence of the assumption that international transfers between governments are excluded. If these unrequited transfers were admitted and optimally chosen, it would obviously be the case that $\lambda^{*}=\Lambda^{*}$.
} 
(A.4) by $e_{q q}^{*} t^{*}$ and $E_{Q Q}^{*} T^{*}$, respectively, to obtain, again in obvious notation

$$
m r s_{g}^{*}+M R S_{g}^{*}=\frac{\alpha}{\beta} m r t_{g}^{*}
$$

where $\alpha \equiv t^{* \prime} e_{q}^{*}$ and $\beta \equiv t^{* \prime} e_{q}^{*}+t^{* \prime} e_{q q}^{*} t^{*}$. With $t^{* \prime} e_{q}^{*}$ and $t^{* \prime} e_{q q} t^{*}$ being scalars (the former being positive from the budget constraint (4) and the latter strictly negative since $e_{q q}$ is a negative definite matrix) it follows that $\alpha / \beta>1$ and, thus, in the presence of secondbest optimal commodity destination-based taxes global public goods are underprovided ${ }^{32}$ relative to the Samuelson first-best rule. ${ }^{33}$

Taking into account (2)-(5), the Ramsey taxes in (A.4) are implicitly characterized as the solutions to the following system of equations

$$
t^{* \prime}=\psi^{\prime}\left(t^{*}, T^{*}\right) \quad ; \quad T^{* \prime}=\Psi^{\prime}\left(T^{*}, t^{*}\right) .
$$

It is the functional forms $\psi(t, T)$ and $\Psi(T, t)$ that are key to argument in the main text. (6) are simply (A.7) evaluated at arbitrary tax levels. Substituting (A.7) - evaluated at an arbitrary equilibrium - into the sum of (A.3) and its foreign counterpart gives (9).

\footnotetext{
${ }^{32}$ Equation (A.6) is the so-called modified Samuelson rule, characterizing the optimal provision of (here extended to) home country global public good under the conditions that there are no income effects and demand and supply of the taxed goods are independent of global public good provision. On this see Atkinson and Stern (1974).

${ }^{33}$ Strictly speaking, this statement cannot be taken to imply that the amounts of the global public good are lower than those that would be provided in the first-best situation where lump-sum taxes are available. Underprovision is simply taken to be that, for the home country, $m r s_{g}^{*}+M R S_{g}^{*}>m r t_{g}^{*}$ (and $m r s_{G}^{*}+M R S_{G}^{*}>M R T_{G}^{*}$ for the foreign one).
} 


\section{Appendix B: Clarifying footnote 20}

This Appendix shows that starting from an arbitrary tax-distorted equilibrium with $t \neq T$, a coordinating reform by which both countries (or at least one of them) approach their Ramsey taxes, will entail a potential Pareto improvement if the initial tax structures are close enough to the optimal ones. To see this add and subtract the optimal tax rates in (9) to obtain

$$
\begin{aligned}
d W & =\frac{1}{\lambda}\left[\left(t-t^{*}\right)+\left(\psi\left(t^{*}, T^{*}\right)-\psi(t, T)\right)\right]^{\prime} e_{q q} d t \\
& +\frac{1}{\Lambda}\left[\left(T-T^{*}\right)+\left(\Psi\left(T^{*}, t^{*}\right)-\Psi(T, t)\right)\right]^{\prime} E_{Q Q} d t
\end{aligned}
$$

Clearly, then, the change in global welfare thus depends upon

- The deviation of the Ramsey taxes $t-t^{*}$ and $T-T^{*}$ from the initial ones and,

- the deviation of $\psi\left(t^{*}, T^{*}\right)$ from $\psi(t, T)$ and $\Psi\left(T^{*}, t^{*}\right)$ from $\Psi(T, t)$.

Take now the reform

$$
\left[\begin{array}{c}
d t \\
d T
\end{array}\right]=\left[\begin{array}{c}
\alpha\left(t^{*}-t\right) \\
A\left(T^{*}-T\right)
\end{array}\right],
$$

with $\alpha, A \geq 0$, that is, a non-uniform proportional reduction of the gap between $t(T)$ and its optimal value $t^{*}\left(T^{*}\right)$ by at least one of the countries. If the latter deviations are zero, the change in global welfare after the reform (B.2) reduces to

$$
d W=-\frac{\alpha}{\lambda}\left(t-t^{*}\right)^{\prime} e_{q q}\left(t-t^{*}\right)-\frac{A}{\Lambda}\left(T-T^{*}\right)^{\prime} E_{Q Q}\left(T-T^{*}\right)>0,
$$

and the reform will deliver a potential Pareto improvement. This simply says is that if the starting point is close enough to the optimum then there will always be a coordinating tax reform that delivers a global welfare gain. Though insightful, this in a very real sense and as a practical matter, quite restrictive since it requires that the arbitrary initial tax equilibrium is in the neighbourhood of the global optimum: if they are further apart, then the sign of $d W$ after the reform (B.2) is indeterminate. 


\section{Appendix C: Derivation of the non-cooperative taxes in (13) and proof that $m r s_{g}^{N}>m r t_{g}^{N}$}

This Appendix utilizes Appendix A. At a non-cooperative equilibrium each country's tax structure maximizes its own welfare taking the tax vector of the other country as given. For the home (foreign) country setting $d T=0_{M}\left(d t=0_{M}\right)$ and maximising by setting $e_{u} \partial u / \partial t=0_{M}\left(E_{U} \partial U / \partial T=0_{M}\right)$ in (A.3) (and its foreign counterpart) gives (13) for the home (foreign) country.

As stated in the main text, $\pi^{N} \in(0,1)\left(\Pi^{N} \in(0,1)\right)$. Consequently, at the noncooperative equilibrium global public goods are underprovided relative to the Samuelson first-best rule (under the conditions that there are no income effects on the non-numeraire goods and demand and supply of taxed goods are independent of global public good provision). That $\pi<1$ ( $\Pi<1$ ) follows from post-multiplying (13) by $e_{q q}^{N} t^{N}$ and rearranging, after making use of the fact that $m r s_{g}^{N}=-e_{g}^{N}$ and $m r t_{g}^{N}=-r_{g}^{N}$, to obtain $m r s_{g}^{N}=\frac{\delta^{N}}{\zeta^{N}} m r t_{g}^{N}$, where $\delta^{N} \equiv t^{N^{\prime}} e_{q}^{N}$ and $\zeta^{N} \equiv t^{N \prime} e_{q}^{N}+t^{N \prime} e_{q q}^{N} t^{N}$. Since $t^{N^{\prime}} e_{q}^{N}>0$ (following from (3)) and $t^{N^{\prime}} e_{q q}^{N} t^{N}<0$ (following from the fact that $e_{q q}^{N}$ is a negative semi-definite matrix), we will have $\delta^{N} / \zeta^{N}>1$, implying that $m r s_{g}^{N}>m r t_{g}^{N} \cdot \delta^{N} / \zeta^{N}$ is termed the private marginal cost of public funds because it disregards the marginal valuation of the other country. It, thus, follows that $\pi^{N}=\zeta^{N} / \delta^{N}<1$ (and similarly for the foreign country $\left.\Pi^{N}=Z^{N} / \Delta^{N}<1\right)$. That $\pi>0(\Pi>0)$ follows from the properties of the revenue and expenditure functions. 


\section{References}

Abe, K, 1992, Tariff reform in a small open economy with public production, International Economic Review, 30, 209-222.

Atkinson, A. B., and N. Stern, 1974, Pigou, taxation and public goods, Review of Economic Studies, 41, 119-128.

Cnossen, S., 1990, The case for tax diversity in the European Community, European Economic Review, 34, 471-479.

Dahlby, B., 2008, The marginal cost of public funds. Theory and applications. M.I.T. Press, Cambridge, Mass.

Delipalla, S., 1997, Commodity tax harmonization and public goods, Journal of Public Economics, 63, 447-466.

Dixit, A. K., and V. Norman, 1980, Theory of international trade. Cambridge: Cambridge University Press.

Kotsogiannis, C. and M-A. Lopez-Garcia, 2007, Imperfect competition, indirect tax harmonization and public goods, International Tax and Public Finance, 14 (2), $135-149$.

Karakosta, O., C. Kotsogiannis, and M-A. Lopez-Garcia, 2014, Indirect tax harmonization and global public goods, International Tax and Public Finance, 21(1), $29-49$.

Keen, M. J., 1987, Welfare effects of commodity tax harmonization, Journal of Public Economics, 33, 107-114.

Keen, M. J., 1989, Pareto-improving indirect tax harmonization, European Economic Review, 33, 1-12.

Keen, M. J., S. Lahiri, and P. Raimondos-Møller, 2002, Tax principles and tax harmonization under imperfect competition: A cautionary example, European Economic Review, 46, 1559-1568.

Keen, M. J., and D. Wildasin, 2004, Pareto-efficient international taxation, American Economic Review, 94, 259-275.

Lahiri, S., and P. Raimondos-Møller, 1998, Public good provision and the welfare effects of indirect tax harmonisation, Journal of Public Economics, 67, 253-267.

Lockwood, B, 1997, Can commodity tax harmonisation be Pareto-improving when governments supply public goods?, Journal of International Economics, 43, 387-408.

Lopez-Garcia, M-A., 1996, The origin principle and the welfare gains from indirect tax harmonization, International Tax and Public Finance, 3, 83-93.

Lopez-Garcia, M-A., 1998, On welfare and revenue effects of indirect tax harmonization, Economics Letters, 60, 185-193. 
Neary, P., 1993, Welfare effects of tariffs and investment taxes, in W.J. Ethier, E. Helpman and J.P. Neary (eds.): Theory, Policy and Dynamics in International Trade: Essays in Honor of Ronald W. Jones, Cambridge: Cambridge University Press, 131-156.

Redoano, M., 2014, Tax competition among European countries. Does the EU matter? European Journal of Political Economy, 34, 353-371.

Sandmo, A., 2006, Global public economics: Public goods and externalities, Economie publique/Public Economics 18, 3-21.

Scott, A., 1987, Tax harmonization in the comparison of federal and other states, European Journal of Political Economy, 3, 219-249.

Turunen-Red, A., and A. Woodland, 1990, Multilateral reforms of domestic taxes, Oxford Economic Papers 42, 160-186.

Woodland, A., 1982, International trade and resource allocation, New York: NorthHolland. 